\title{
A história NA CULTURA, A CULTURA NA HISTÓRIA: ELEMENTOS PARA UMA ANÁLISE COMPARATIVA ENTRE WALTER BENJAMIN E Gianni VATtimo
}

\section{Clóvis Da Rolt ${ }^{1}$}

\begin{abstract}
Resumo
Este artigo pretende abordar, mediante uma perspectiva comparativa, algumas questões sobre o pensamento de Walter Benjamin e Gianni Vattimo, no que se re fere às suas concepções de história, tendo como eixo central a noção de cultura. A rejeição de Benjamin em levar adiante o continuísmo historicista, que marcava a cultura ocidental em fins do século 19 e início do século 20, leva 0 autor a formular novas posições teóricas para se pensar a história não mais como progresso e concatenação objetiva de fatos, mas como precarização e catástrofe. Por outro lado, mediante uma abordagem de cunho hermenêutico, Vattimo propõe olhar para a história de forma a desvinculá-la da solidificação factual e da objetividade, visto que ela só pode ser acessada como um texto, mediante um ato interpretativo.
\end{abstract}

Palavras-chave: História.Cultura. Benjamin. Vattimo

${ }^{1}$ Doutorando em Ciências Sociais pela Unisinos. End. eletrônico: cdarolt@hotmail.com 


\section{History IN THE CULTURE, CULTURE IN HISTORY: ELEMENTS FOR A COMPARATIVE ANALYSIS BETWEEN WALTER BENJAMIN AND Gianni VatTimo AbSTRaCT}

This article focuses, upon a comparative perspective, some questions about Walter Benjamin's and Gianni Vattimo's thoughts, concerning their ideas of history, having as its central axis the notion of culture. The rejection of Benjamin to advance the continuity of historicism, which marked the western culture in the late 19th and early 20th century, leads the author to formulate new theoretical positions to think about the story not as progress and concatenation of objective facts, but as instability and disaster. Moreover, through a hermeneutic approach to nature, Vattimo proposes to look at history in order to unlink it from the solidification of the facts and objectivity, since it can only be accessed as a text by an interpretive act.

Keywords: History.Culture. Benjamin. Vattimo

\section{Primeiras palavras}

$\mathrm{N}$

0 âmbito da modernidade, a cultura ocidental alimentou continuamente a premissa de que a história estava presente tanto nos mínimos fragmentos de inteligibilidade como também nas grandes epopéias culturais. Buscavase, por meio da história, a construção de uma unidade sócio-temporal que pudesse ser acessada como herança legítima, organizada a partir dos dados objetivos do mundo vivido sob a ótica da evolução e do progresso.

A história, no contexto das sociedades modernas, encontrava no formato do museu a sua fisionomia exemplar ao considerá-lo o espaço onde se conservavam cadáveres culturais rejuvenescidos por sucessivas camadas de verniz. Num contexto filosófico, a verdade poderia ser tangenciada se elegesse a história como suporte e, com ela, constituísse um quadro analítico atado às noções de aprimoramento, desenvolvimento ético e superação.

A modernidade construiu-se com base na idéia de que a evidência que se podia extrair de um fenômeno, mediante provas e corroborações metodologicamente conduzidas, era a certeza de seu caráter acabado, livre de contradições e impermeável às impurezas de qualquer outra forma de leitura que ousasse profanar os templos da ciência, nos quais a história ocupava o púlpito. 
Este contexto não esteve livre de contradições e combates, manejados por diversos pensadores e por suas concepções sobre a potência da história - como veículo centralizador da própria inteligibilidade do mundo e como condição sine qua non para acessar o real mediante uma consciência receptora do grande relato que comportava um sentido coeso para a existência social. Sobre este aspecto com a devida atenção aos contrastes que esta temática demanda -, pode-se citar as figuras de Hegel, Comte e Marx, cujas formulações teóricas concedem grande credibilidade à história, no sentido de descrevê-la como a área de confronto e 0 eixo aglutinador de outras temáticas, ou mesmo como instância de validação de argumentos e teses fundacionais.

No caso de Hegel, a história converte-se no suporte do Espírito, no canal que permite o desdobramento dialético do ser como gradual efetivação da liberdade; em Comte, a história adquire os contornos de um ente manipulável que, associado à ciência, deve internalizar o propósito de abandonar a antiga carcaça em busca de uma roupagem mais evoluída: a culminação positiva; Marx, por outro lado, vê na história o livro em que se escreveu um projeto de dominação, cujo antídoto não aparece no apêndice. Para ele, a história é permanente luta, estado constante de tensão dos opostos. É nela que se inscreve a visibilidade da dominação como registro que se perpetua no tempo, independente das configurações culturais que a dominação pode assumir.

Proponho-me, com este artigo, a discutir alguns aspectos do pensamento de Walter Benjamin e Gianni Vattimo relativos às suas concepções de história e à forma como as articulam frente a uma dimensão cultural. Nesse sentido, talvez fosse necessário partir de uma revisão da história como instância alocada em diferentes níveis de percepção, pautada em diversas matrizes ideológicas ou embasada em múltiplas posições, desde as mais tolhedoras até as mais emancipatórias. Por certo, isso exigiria um processo diferente do que pretendo fazer aqui, já que tomo como ponto de partida o rompimento benjaminiano com uma visão de história progressista e salvífica, tradicionalmente alinhada aos preceitos instituídos pela modernidade.

Portanto, o olhar sobre a temática aqui proposta não é retroativo numa dimensão de longo alcance; isso quer dizer que a aproximação comparativa que proponho tem como pano de fundo o quadro desestabilizado (talvez desestabilizador) dos discursos sobre a história e suas dinâmicas frente a processamentos de ordem cultural. Assim, o pensamento de Benjamin é captado aqui como um divisor de águas que, de um lado, abandona a percepção da história 
como bloco homogêneo e passível de ser reproduzido por ser o locus da experiência legitimada e, do outro, sugere que a história não passa de um cenário de onde se pinçam os elementos presentes numa determinada forma de narrar o mundo.

Quanto ao pensamento de Vattimo, também cabem algumas ressalvas. Não pretendo, evidentemente, adentrar o seu largo alcance, sobretudo no que se refere à sua incursão nos estudos sobre a pós-modernidade e em suas ramificações, como, por exemplo, suas teorizações sobre os mass media, a arte, Nietzsche e Heidegger. Trarei ao debate, portanto, algumas questões da perspectiva hermenêutica deste autor que, segundo penso, minam os arcabouços modernos do pensamento fundacional sobre a história ao rejeitar a idéia de que há "fatos" e, como conseqüência, ao duvidar de que pode haver correspondências factuais criadoras de discursos mais autênticos ou mais alinhados a uma suposta "verdade histórica" que se conserva como meta a ser alcançada pelo desdobramento da existência humana inscrita no tempo.

A aproximação que proponho justifica-se pelo caráter anti-linear com que os dois autores em questão lançam suas teses em relação à história, de modo a suspeitar de supostos integralismos ou finalismos narrativos. Não busco um alinhamento ou uma filiação intelectual comum a ambos, o que seria pouco provável considerando a ênfase marxista do pensamento de Benjamin em contraste com a ênfase discursiva de Vattimo; tampouco penso em reduzir as críticas de Benjamin à desconstrução pós-moderna que vem, de um modo geral, contestando a noção de "objetividade histórica", já que, em Benjamin, a intenção da quebra da homogeneidade histórica está inscrita no âmbito do rompimento com as tradições teóricas e políticas da II e III Internacionais Comunistas, em cuja crença no progresso necessário da história Benjamin visualizava um conjunto de práticas destrutivas e desumanas ligadas ao capitalismo. 0 que Benjamin tenta, de um modo geral, é redesenhar a crítica revolucionária na esteira da modernidade capitalista.

Sugiro que os dois autores realizam tarefas de reorganização conceitual em relação a um domínio que, no âmbito da modernidade, refugiava-se no interior de sua blindagem e de sua auto-referência. Benjamin implode o trono auto-suficiente da história ao romper com o relato oficial, ao propor que o derrotado também seja ouvido e ao sugerir que as impurezas e os ruídos sejam vistos como novos espaços de onde também pode surgir um relato histórico. Vattimo, paramentado com as vestes da hermenêutica - embora não fale explicitamente de uma filosofia da história -, faz com que sua abordagem sobre este conceito apareça nas entrelinhas 
de sua leitura sobre a debilidade ontológica advinda da dissolução da metafísica, que traz consigo uma proposta de descanonização dos centros oficializadores dos grandes relatos modernos e do critério de universalidade que lhes servia de suporte.

\section{WALTER BENJAMIN: QUE HISTÓRIA A HISTÓRIA CONTA?}

Os heterônimos do poeta Fernando Pessoa poderiam ser também a marca intelectual de Benjamin. No pensamento do alemão de origem judia convivem o filósofo, o crítico, o místico e o esteta, ambos cadenciados pelas vicissitudes de uma postura intelectual pluralista, fator que comumente lhe rende críticas negativas. Os textos de Benjamin têm a inquietude de quem atravessa mares revoltos e transita pelos interstícios de dois séculos, absorvendo a decadência de um e a euforia do outro. A arte e a técnica, o teatro épico, a fotografia, o fascismo, as teses sobre a história, tudo convive em Benjamin tendo como ponto de coesão certa negligência metodológica e uma aparente displicência, a julgar por sua forma de filtrar a realidade por meio do turbilhão de signos que gravitam no universo da cultura. Em Benjamin, o misticismo e o messianismo não são saídas fáceis para desviar as atenções amplamente focalizadas na razão e nos discursos factuais dos defensores da técnica e do progresso; pelo contrário, o recurso ao misticismo sugere uma busca, por parte do autor, que transcende a explicação das dinâmicas sociais pelo mero jogo de causas e conseqüências e que almeja uma integração holística, uma fusão entre matéria e espírito. Nesse sentido, seu marxismo é impregnado de contrapesos devido ao fato de ele não negar o intuicionismo e as imagens utópicas em direção a um projeto revolucionário marxista.

A história, para Benjamin, deixa para trás vazios e buracos, ou melhor, constrói-se a partir deles. Löwy (2002, p. 199) aponta que a filosofia da história de Benjamin advém de três fontes, "o romantismo alemão, o messianismo judeu e o marxismo. Não é uma combinatória ou 'síntese' dessas três perspectivas (aparentemente) incompatíveis, mas a invenção, a partir delas, de uma nova concep̧̧ão, profundamente original." Esta "nova concepção" à que se refere Löwy está diretamente ligada à ruptura com o progressismo e com o historicismo, contra os quais Benjamin institui sua visão da história como área de desnível e descontinuidade, como campo que dá lugar à imanência das imagens periféricas, intuitivas e de baixo espectro, as quais ocupavam no quadro evolutivo uma função importante, apesar de serem negadas pela perspectiva evolucionista da burguesia européia. 
Em textos benjaminianos, como "Experiência e Pobreza" e "0 Narrador", transparecem as angústias do autor no que se refere a uma espécie de desgaste da originalidade e da autenticidade de um mundo devorado pela técnica e por seus subprodutos concatenados à ação histórica de uma práxis meramente funcional. "Uma nova forma de miséria surgiu com esse monstruoso desenvolvimento da técnica, sobrepondo-se ao homem”, diz Benjamin (1994 p. 115). Miséria parece ser o termo chave para se compreender o resultado da história progressista combatida por ele, cujos avatares unificadores deixavam transparecer, como seqüelas, a pobreza da experiência. Não se trata da miséria física, da miséria do corpo faminto e exposto ao perigo da precarização: é da miséria espiritual e cultural que fala Benjamin, da miséria de se pensar o mundo como fluxo de signos que caminham para um mesmo fim, rumo a igualitarismos estereotipados. E mais, há claras referências em sua abordagem sobre a transmissão geracional do patrimônio cultural como prática que está intimamente ligada à noção de experiência, ou seja, como prática que liga o passado vivido através das experiências que lhe capturam a um presente em que essas experiências são transformadas, de modo que ambas enriqueçam-se mutuamente. A ruptura desta relação, encarada por Benjamin de forma nostálgica, anuncia o lugar da técnica na civilização do século 20. Do modo como esclarece Gatti (2009, p. 173), a partir de uma interpretação de Benjamin, uma verdadeira experiência

é uma especial conjunção, na memória, entre traços do passado individual e do passado coletivo. A experiência está condicionada à atividade de rememoração que instaura a possibilidade de que o passado individual se insira no contexto mais amplo da comunicação entre gerações sucessivas que formam a tradição. A rememoração, para estabelecer essa conjunção, necessita, por sua vez, de uma noção plena de tempo capaz de estruturar uma concepção decisiva de presente que se descubra na sua possibilidade de entrar em contato com o passado e retomar experiências que esse passado the transmite. Mas essa retomada só é possível caso o presente reflita sobre essa distância fundamental que o separa e o torna diferente do passado.

Benjamin traça um profundo quadro das forças estéticas atuantes nas primeiras décadas do século 20 para, a partir delas, pensar como a cultura organiza os espaços e os contatos humanos por meio dos produtos que ela cria. Mais do que se conformar com uma leitura oficial do momento histórico em que está inserido, Benjamin procura extrair da cultura os elementos argumentativos para imergir na história e sustentar que ela pode ser fonte de brutalidades se não der espaço para múltiplos protagonismos. Deste modo, o patrimônio cultural é percebido por 
Benjamin como resultado do levante histórico dos vencedores e, portanto, ele não corresponde, numa relação de identidade, à totalidade da humanidade que move a engrenagem da história, mas somente àquela parcela que se identifica com os dominadores e com seus valores excludentes. Assim, segundo escreve Benjamin (2004, p. 52),

os que dominam no momento são os herdeiros de todos os que outrora venceram. Por isso, a empatia com o vencedor favorece em cada caso 0 dominador do momento. (...) Quem quer que tenha vencido até o dia de hoje, caminha no cortejo triunfal que leva aos dominadores de hoje sobre os vencidos que hoje estão depostos ao chão. Os despojos, como sempre foi usual, são arrastados no cortejo. Eles são designados como patrimônio cultural.

A questão central que se pode extrair desta orientação é de extrema pertinência, pois se a história não possui um centro organizador da experiência coletivamente vivida em sociedade, mediante o qual ela possa administrar os recursos da transmissão cultural, então é provável que todas as formas de vida social, em todos os seus diversos arranjos, símbolos, conteúdos e manifestações são igualmente participantes da globalidade cultural, o que não quer dizer que todas gozem da mesma projeção. Creio que, dentre outras motivações, o estudo atento da obra de Proust, bem como sua tradução para o alemão, são testemunhos da visão que Benjamin tinha da história, a qual pode ser associada à indeterminação temporal da obra proustiana e ao seu caráter de texto aberto, o qual se pode acessar de inúmeras formas².

Conforme pontua Hall, a cultura é uma área que traz implícita a idéia de deslocamento, o qual já está anunciado em Benjamin a partir de sua desconfiança em relação ao caráter fixo legado do essencialismo moderno. A abordagem que um pensador contemporâneo como Hall (2003, p. 44) elabora ao dizer que "estamos sempre em processo de formação cultural" e que "a cultura não é uma questão de ontologia, de ser, mas de se tornar", deve muito ao pensamento de Benjamin, principalmente no sentido de que, para o crítico alemão, a cultura ocorre como fruto de complexas relações travadas em diferentes esferas sociais, mediante disparidades de acesso ao poder.

A visão abrangente que Benjamin elabora da história é o que lhe permite conceber a cultura como espaço que não está isento de contradições e violências,

${ }^{2}$ Para melhor compreender a aproximação de Benjamin com a obra de Proust, ver o ensaio de 1929 "A imagem de Proust" (BENJAMIN, 2004, p. 36-49). 
sobretudo quando, por meio dela, o historicismo tenta legitimar sua ação civilizatória sem considerar os desníveis que marcam o processo social. Assim, Benjamin (2004, p. 63) declara que o historicismo carece de armação teórica, pois "seu proceder é aditivo: alimenta a massa dos fatos para preencher o tempo homogêneo e vazio." Esta orientação fundamental da perspectiva benjaminiana coloca-se diretamente em choque com o pensamento progressista que encara a cultura como um benefício ou como uma instância moralizadora e impregnada de premissas civilizadoras, potencialmente voltadas para o aprimoramento do espírito humano. A cultura, para Benjamin, é um fenômeno que fala por meio de suas reminiscências, as quais constituem elementos que a história organiza por meio de discursos que não são fixos ou legítimos por si só, visto que são interpretações agenciadas num campo de poderes.

Sob muitos aspectos, o debate contemporâneo voltado para a relação entre história e cultura continua motivando um olhar crítico para a história de modo a não encará-la como uma instância auto-contida. Santos, por exemplo, admite a necessidade de constantes reformulações sobre as construções oficiais da cultura, sobretudo no que se refere ao conceito de "cultura nacional". Sob esta questão, Santos (2008, p. 148) sugere três orientações metodológicas.

A primeira é que, não sendo nenhuma cultura auto-contida, os seus limites nunca coincidem com os limites do Estado; o princípio da soberania do Estado nunca teve um correspondente no domínio da cultura. A segunda é que, não sendo auto-contida, nenhuma cultura é indiscriminadamente aberta. Tem aberturas específicas, prolongamentos, interpenetrações, interviagens próprias, que afinal são o que de mais próprio há nela. Finalmente, a terceira orientação metodológica é que a cultura de um dado grupo social não énunca uma essência. É uma auto-criação, uma negociação de sentidos que ocorre no sistema mundial e que, como tal, não écompreensível sem a análise da trajetória histórica e da posição desse grupo no sistema mundial.

A consciência de que temos uma história despertou por volta do século 16, fortemente impulsionada pela ciência e pela idéia de que, por meio da história, seria possível civilizar o ser humano e diferenciá-lo das demais espécies vivas por meio de sua racionalidade. Contudo, vemos que este princípio pode ter gerado uma práxis social em que a história alinhou-se à opressão e ao lugar da fala dos mais fortes e poderosos. Benjamin (2004, p. 52) sintetizou a relação conflituosa da história com a transmissão cultural em sua célebre afirmação: "não há um 
documento de cultura que não seja também um documento de barbárie.” Tanto a história quanto a cultura que lhe segue acoplada não têm valor universal, não são essências ou campos auto-referentes. Ao contrário, a partir delas, podemos exercitar nossas desconfianças a fim de pensarmos no mundo como abertura e como espaço onde a vida transcorre sob muitas indefinições.

No interior de um cenário moderno, o pensamento de Benjamin sobre a história foi recebido como um aviltante programa anti-burguês, sobretudo porque sua perspectiva de uma história desprovida de naturalizações e de qualquer sentido de autonomia passou a gozar de grande influência junto à globalidade da produção intelectual da Escola de Frankfurt.

\section{Gianni Vattimo: dos idiomas aOS dialetos}

Conforme foi mencionado anteriormente, Gianni Vattimo não possui uma produção específica relacionada à filosofia da história num sentido stricto sensu. Não obstante este aspecto, seus argumentos e teses sobre a transição da modernidade para a pós-modernidade consideram a história um elemento balizador de grande potência e alcance, especialmente devido à sua abordagem hermenêutica. Vattimo não concede à história um valor universal, cuja formulação seja transmissível de forma direta de uma geração a outra ou de um contexto histórico-cultural a outro sem que suas bases sejam profundamente avaliadas. A perspectiva hermenêutica adotada por Vattimo (1996a, p. 109) está bastante clara conforme pontua o autor ao dizer que

uma lógica 'hermenêutica busca a verdade como continuidade, "correspondência", diálogo entre os textos, e não como conformidade do enunciado a um estado mítico das coisas. Esta lógica é tão mais rigorosa quanto menos se deixa impor como definitivo um determinado sistema de símbolos, uma determinada narração.

Também a centralidade de uma "verdade" objetivada na perspectiva do progresso e do aperfeiçoamento é contestada pela hermenêutica de modo a dar espaço para a negociação do sentido das práticas humanas no âmbito de sua interpretação e de suas circunstâncias. 0 caráter interpretativo das funções hermenêuticas exercita-se numa profunda vinculação com a linguagem, instância que produz a coesão da experiência humana ao mesmo tempo em que a torna difusa. Este dado, segundo Ricoeur (1983, p. 41), "significa que minha pertença a uma tradição ou a tradições passa pela interpretação dos signos, das 
obras, dos textos, nos quais se inscreveram e se ofereceram à nossa decifração as heranças culturais."

Na perspectiva de Vattimo, a história, no âmbito da pós-modernidade, perde seu estatuto ontológico e sua incursão determinante no plano da cultura para se tornar uma instância cerceada pela relativização própria de uma racionalidade hermenêutica. Isso nos leva a pensar a história como configuração textual impregnada de variantes simbólicas, semânticas e, certamente, como instância atrelada à própria condição de pluralidade da cultura humana que a produz. Vattimo chama a atenção para as correntes teóricas contemporâneas que se referem à dissolução da história e à perda de sua função unificadora, especialmente no contexto do enfraquecimento da metafísica a partir de Nietzsche e Heidegger. Segundo o filósofo italiano (1996b, p. 14), "dissolução significa ruptura da unidade, e não fim puro e simples da história. Percebeu-se que a história dos eventos - políticos, militares, dos grandes movimentos de idéias - é apenas uma história entre outras."

No que tange especialmente às questões culturais da modernidade, as teorias contemporâneas são hábeis em situá-las no âmbito de um projeto emancipador, impulsionado pela categoria do "novo" e do aprimoramento da sociedade num sentido considerado naturalmente ascendente. A modernidade é a época dos grandes relatos e dos vínculos progressistas da história com uma sociedade que possui uma "missão" e que, mediante a concentração nos fundamentos e nas essências, quer banir para fora da humanidade qualquer prática considerada ilegítima. Conforme explica Vattimo (1994, p. 161),

diferentemente do historicismo metafísico do século 19 (Hegel, Comte, Marx), a hermenêutica não pensa que o sentido da história seja um "fato" que se deva conhecer, a favorecer e a aceitar (...); o fio condutor da história aparece ou ocorre somente no interior de um ato interpretativo que adquire validade no diálogo com outras interpretações possíveis.

$\mathrm{Na}$ perspectiva deste autor, se a modernidade é idiomática, a pósmodernidade é dialetal. A história, neste contexto, passa de uma condição de lugar de fala do universal para o lugar de fala do local, sem que isso signifique um decréscimo ou um declínio no processamento da cultura. Para Vattimo, está muito claro que a configuração social pós-moderna rompe com a categoria do "novo", tipicamente moderna, para dar lugar à experiência de fim da história onde não há categorizações e onde não se busca a apresentação de uma etapa diferente, mais evoluída ou mais retrógrada da própria história. (VATTIM0, 1996b, p. 9) 
0 acesso aos quadros históricos, numa perspectiva hermenêutica, ocorre como relação intertextual de discursos e práticas de produção de sentido. Gargani (1994, p. 92) escreve que a racionalidade do discurso hermenêutico consiste

em reunir palavras surgidas no espaço da ausência, no encontro de sua recíproca implicação fora de um código de verificação determinado com anterioridade e que, portanto, não pertencem a uma ordem de previsão estabelecida; 0 discurso hermenêutico não realiza uma concatenação mecânica de conceitos, mas a coexistência das palavras, recursos, signos e vestígios que é a manifestação de um destino possível do sentido.

Sobre estes aspectos, a tese que Vattimo defende é a de que, na sociedade dos mass media, abriu-se caminho para um ideal de emancipação em cuja base estão a oscilação, a pluralidade e a erosão do princípio de realidade, elementos que se contrapõem a uma suposta auto-consciência sobre um mundo estável e cujas estruturas, ilusoriamente, acreditávamos ser possível acessar mediante a apreensão do que elas "são" ou do modo como "estão" dadas à experiência (VATTIM0, 1996a, p. 82). É nítida a crítica de Vattimo aos enquadramentos históricos da metafísica e à relação desta com a possibilidade de acessar um mundo sempre disponível como dado objetivo e ontologicamente contínuo no tempo e no espaço. Tal crítica expõe um dos princípios centrais da hermenêutica e sua perspectiva anti-fundacional.

Vivemos um momento em que a configuração das relações humanas está visivelmente modificada. Os padrões de conduta que moldaram a sociedade moderna estão em declínio. A vida atual, tanto em sua dimensão individual quanto coletiva, transformou-se em algo cuja natureza é insatisfatória, incerta e sem um sentido fixo traduzido pela história. Na experiência de fim da história, não se almeja chegar a lugar algum, pois não há um ideal mais verdadeiro ou uma moral mais correta a serem cultuados e transmitidos a outras gerações. 0 próprio conceito de "geração" passou ser problemático.

No plano prático, podemos ver como a experiência de fim da história se manifesta na insatisfação constante que desenvolvemos com a aparência do nosso corpo (cirurgias plásticas, mudança de sexo, dietas de emagrecimento); em nossas atividades profissionais que podem variar em curtos espaços de tempo (descrédito à formação acadêmica, hiper-valorização da experiência momentânea e nãotransmissível, migrações profissionais, fim das carreiras); nos arranjos familiares atuais e suas expressões anti-tradicionais (casais homossexuais, mães solteiras por opção de vida, inseminação por meio de bancos de sêmen); na queda dos modelos éticos de perenidade e sua substituição por modelos provisórios e descartáveis, 
consumidos ao bel prazer da situação (ídolos da indústria do entretenimento e dos meios de comunicação de massa, discurso de lideranças políticas e religiosas); na mobilidade humana que faz as pessoas circularem pelo globo dando vida aos muitos dialetos capazes de narrar a existência e elevá-la a uma profusão de símbolos, relatos, discursos e sentidos (turismo, migrantes em busca de trabalho, refugiados políticos); em experiências religiosas que, muitas vezes, são apreendidas como práticas itinerantes em busca da divindade mais eficaz ou capaz de agir com mais imediatismo (sincretismo religioso, iniciação em várias religiões, esoterismo); na aceleração das percepções acerca do tempo e na necessidade de viver numa espécie de simultaneidade que otimiza as experiências (cursos intensivos de idiomas, faculdades que podem ser cursadas no sistema de educação à distância em pouco mais de um ano, pacotes turísticos do tipo "conheça o Brasil em dez dias", veículos como o Lamborghini Gallardo que vai de 0 km a $100 \mathrm{Km}$ em apenas 3,9 segundos).

Considerando os argumentos de Geertz sobre as articulações culturais na contemporaneidade, percebe-se o quanto a perspectiva hermenêutica pode ser fundamental para acessar um mundo no qual as diversas culturas tornaram-se veículos de uma polissemia inesgotável. "A visão da cultura, de uma cultura, desta cultura”, diz Geertz (2001, p. 219),

como um consenso em torno de elementos fundamentais - concepções comuns, sentimentos comuns, valores comuns - parece muito pouco viável, diante de tamanha dispersão e desarticulação; são as falhas e fissuras que parecem demarcar a paisagem da identidade coletiva. Seja o que for que define a identidade no capitalismo sem fronteiras e na aldeia global, não se trata de acordos profundos sobre questões profundas, porém de algo mais parecido com a recorrência de divisões conhecidas, argumentos persistentes ou ameaças permanentes, e com a idéia de que, haja o que mais houver, de algum modo é preciso manter a ordem da diferença.

Não obstante a sensação de que perdemos os referenciais que construíram a modernidade, de que vivemos como peças de um quebra-cabeça que não forma a imagem primordial e teleológica de um mundo estático, Vattimo percebe na pósmodernidade uma abertura para um tipo de emancipação desacoplada da lógica moderna que forçava as identidades e os protagonismos sociais a enquadrarse em idiomas universais. Um dos conceitos mediante o qual Vattimo discute uma possível emancipação frente à pós-modernidade está associado à noção de 
polifonia operada pelos mass media, ou seja, para o autor, "dialeto" é a palavrasíntese da pós-modernidade. De acordo com Vattimo (1996a, p. 84),

em que consiste, portanto, concretamente, o possível alcance emancipador e libertador da perda de sentido da realidade, da autêntica erosão do princípio de realidade no mundo dos mass media? Aqui, a emancipação consiste, certamente, em um estranhamento, que é, ao mesmo tempo, um liberar-se por parte das diferenças, dos elementos locais, de tudo o que poderíamos chamar, globalmente, o dialeto [grifo nosso]. Enquanto cai a idéia de uma racionalidade central da história, o mundo da comunicação generalizada estala em uma multiplicidade de racionalidades "locais" - minorias étnicas, sexuais, religiosas, culturais ou estéticas - que tomam a palavra a menos que sejam silenciadas e reprimidas pela idéia de que há uma só forma verdadeira de realizar a humanidade em detrimento de todas as peculiaridades, de todas as individualidades limitadas, efêmeras e contingentes.

0 assombro causado pelas mudanças sócio-estéticas do mundo moderno, que conservava um sentido projetivo de futuro ou de continuidade geracional, dissolveu-se frente às investidas niilistas e pós-metafísicas da contemporaneidade. Se o homem já soube, outrora, quem ele era, hoje ele se pergunta por quem ele pode ser. A principal ruptura surgida com a pós-modernidade diz respeito à percepção do ser como possibilidade, como instância metamorfoseada e sem condicionamentos que lhe impeçam de narrar-se a si próprio, sem dependência da autoridade, da outorga ou da validação de outrem. Para Vattimo, as fundações existenciais de uma perspectiva pós-moderna estão localizadas no debilitamento da força ontológica moderna que, associada ao enfraquecimento da noção de história como catalisadora da razão objetiva, conduziu a um cenário radicalmente modificado, em que se insere a "sociedade transparente." Assim, Vattimo (1996a, p. 78) escreve:

Junto com o fim do imperialismo e o colonialismo, outro grande fator resultou determinante para a dissolução da idéia de história e para o fim da modernidade: trata-se do advento da sociedade da comunicação. Isso desemboca num segundo ponto, que se refere à "sociedade transparente." (...) 0 que pretendo sustentar é: a) que no Nascimento de uma sociedade pós-moderna, os mass media desempenham um papel determinante; b) que os mass media cataracterizam uma sociedade não como uma sociedade mais "transparente", mais consciente de si mesma, mais iluminada, mas como uma sociedade mais complexa, inclusive caótica; e finalmente c) que precisamente neste "caos" relativo residem nossas esperanças de emancipação. 


\section{A história Na CUltura, a CUltura Na história}

A relação entre história e cultura é um tema que transpassa a sociedade como uma lança certeira. Questões amplamente discutidas na atualidade, como, por exemplo, a construção das identidades sociais e culturais, o patrimônio histórico, as sociabilidades e os movimentos sociais, quando deslocadas de um enfoque histórico, podem orientar leituras essencialistas ou mesmo desacopladas de um percurso que thes confere diversos sentidos e muitas vias de abordagem.

Quando acessamos a história, acessamos também um campo minado pelas forças sociais que a produzem. Isso quer dizer que a história não está disponível a todas as pessoas sob as mesmas condições de inteligibilidade, bem como mediante a garantia de uma homogeneidade em dispor dos seus registros. Como resultado de uma série de desencadeamentos sociais complexos e inter-atuantes, a história chega até nós em estado gasoso, não totalmente plasmada numa forma sólida e definitiva. Tanto Walter Benjamin quanto Gianni Vattimo - cada um a seu modo e mediante os aparatos teóricos e as perspectivas políticas que lhes são inerentes - executam a tarefa de teorizar sobre o processo de constituição da história imunizados contra a sedução do discurso fácil e da reprodutibilidade factual. 0 ponto de convergência de suas tematizações está firmemente alicerçado na cultura e em suas propriedades reveladoras da ação humana que ocorre mediante profusa riqueza simbólica. É o alicerce cultural que garante a relativização das posições da histórica frente à narração dos acontecimentos, pois não há uma única forma de realizar a humanidade, tampouco de processá-la mediante um relato histórico universal.

Compartilho aqui o entendimento professado por Castoriadis (2009, p. 11), que diz que "a cultura é tudo o que, na instituição de uma sociedade, ultrapassa a dimensão conjuntista-identitária (funcional-instrumental) e que os indivíduos desta sociedade tomam posse positivamente como "valor". 0 termo "valor" deixa transparecer uma das facetas constitutivas da cultura, a qual está ligada à subjetividade e à expectativa de que 0 valor seja partilhado como perspectiva construtora do social e como um de seus elementos fundantes. Um dos problemas da prática historiográfica acaba sendo sinalizado exatamente pela relação da objetividade com a subjetividade, as quais circundam o valor dotando-lhe de ambigüidades. Para Castoriadis (2009, p. 11),

os valores não são dados por uma instância externa, nem descobertos pela sociedade em camadas naturais ou em um céu da Razão. Eles são, em todas as ocasiões, criados pela sociedade considerada como núcleo de sua 
instituição, baliza última e irredutível da significação, pólos de orientação do fazer e do representar social.

Conceber a cultura como um projeto pautado pela mera transmissão acrítica de processos e lógicas de constituição social pode validar uma postura reducionista que não permite evidenciar a complexidade do fenômeno cultural. Por outro lado, uma leitura histórica que toma para si a função de seletividade do valor a fim de operar sua redistribuição num outro contexto, pode gerar profundos equívocos. No contexto da cultura contemporânea, a dúvida de que o progresso ainda constitui um alicerce social primordial entra em rota de colisão com 0 legado moderno da história e sua missão de dar forma palpável à memória e à verdade dos fatos. Nesse sentido, Vattimo (1996a, p. 76) argumenta que "a crise da idéia de história adentra a crise da idéia de progresso: se não há um curso unitário das vicissitudes humanas, não se poderá sustentar, tampouco, que elas avancem rumo a um fim, que efetuem um plano racional de melhorias, educação e emancipação."

A questão do valor propugnada por Castoriadis, aliada à perspectiva de uma história que se abstém de registrar processamentos de ordem cultual num âmbito universal, coloca-nos de frente a um novo cenário, impregnado de possibilidades e problemas antes inexistentes. Em um ensaio escrito em 1978, Castoriadis acena para uma questão central em relação à cultura hodierna, especialmente em sua vinculação ao descartável, ao pastiche e às investidas desestabilizadoras da indústria cultural. "Talvez esteja morrendo", diz o autor,

o que aprendemos a chamar a própria obra de cultura [grifo do autor]: 0 'objeto' durável, destinado por princípio a uma existência temporalmente indefinida, individualizável, assinada pelo menos de direito por um autor, por um meio, por uma datação precisa. Existem cada vez menos obras e cada vez mais produtos [grifo do autor] que compartilham com os outros produtos da época a mesma mudança na determinação de sua temporalidade: destinados não a ter durabilidade, mas a não ter duração nenhuma. (2009, p. 22).

Assim, considerando o que sinaliza Castoriadis: como pensar a história diante do quadro de "imaterialidade" da cultura hodierna que, cada vez mais, substitui o durável inscrito na tradição pelo incorporal inscrito na experiência? Se a escrita da história, no âmbito da modernidade, caminhava lado a lado com a captura e a transmissão do "fato" evidente por meio da cultura, há que se pensar nas condições incertas que determinam o que é um "fato" e nas relações de poder que 0 inscrevem nas categorias da transmissão cultural. As atuais práticas de 
descentralização do discurso histórico podem estar diretamente relacionadas aos novos arranjos sócio-culturais do mundo pós-moderno que, segundo uma leitura hermenêutica, não correspondem à objetivação trans-histórica da metafísica. Para Gadamer (2003, p. 19), este aspecto traz consigo o reposicionamento da consciência histórica que "já não escuta beatificamente a voz que lhe chega do passado, mas, ao refletir sobre a mesma, recoloca-a no contexto em que ela se originou, a fim de ver o significado e o valor relativos que lhe são próprios. Esse comportamento reflexivo diante da tradição chama-se interpretação" [grifo do autor].

Vattimo sugere que a contribuição da hermenêutica em relação ao processamento da história está em trazer para o centro do debate a relação entre a suspeita enraizada em Nietzsche ${ }^{3}$ sobre o "fato" e sua correspondência direta com uma verdade histórica que a ele está acoplada como conseqüência natural e imanente. Ao deslocar a história para o campo da interpretação, abre-se a possibilidade de abordá-la como um texto construído a partir de muitas áreas que lhe conferem sentido, sem que nenhuma possa ser considerada mais legítima ou valorativamente superior em relação às demais. Mesmo assim, considerando a perspectiva relativizadora da hermenêutica, a história não fica livre de refletir um possível corporativismo interpretativo, como explica Santos (2004, p. 109) ao mencionar a existência de monopólios de interpretação, cujo desmantelamento, segundo o autor, deve dar abertura à criação de "mil comunidades interpretativas e não redundar em milhões de renúncias à interpretação."

A despeito de sua ênfase na quebra da linearidade histórica inscrita na perspectiva dos "vencedores" e condutores de uma suposta universalidade factual, pode-se dizer que a crítica de Benjamin opera no plano da dicotomia, pois ela propõe o deslocamento de um contexto a outro, ou seja, sua proposta continua excludente, no sentido de que força a uma escolha polarizada e, talvez, demasiadamente situacionista. Todavia, este não é o momento de levar adiante as implicações do pensamento benjaminiano sobre a história. 0 que parece mais visível, tanto na abordagem de Benjamin quanto na abordagem de Vattimo sobre a questão aqui proposta, é que ambos operam disjunções, suspeitas e revisões, no sentido de problematizar aquilo que muitas vezes é aceito sem maiores considerações críticas.

\footnotetext{
${ }^{3}$ Para uma melhor compreensão da relação de Vattimo com o pensamento nietzscheano, ver SCOPINHO (2004).
} 


\section{REFERÊNCIAS}

BENJAMIN, Walter. Obras escolbidas. Magia e técnica, arte e política. São Paulo: Brasiliense, 1994.

. La dialéctica en suspenso. Fragmentos sobre la historia. Santiago: Universidad ARCIS e LOM Ediciones, 2004.

CASTORIADIS, Cornelius. Janela sobre o caos. Aparecida: Idéias e Letras, 2009.

GADAMER, Hans-Georg. O problema da consciência bistórica. In: FRUCHON, Pierre (org.). Rio de Janeiro: Editora FGV, 2003.

GATTI, Luciano. Experiência da transitoriedade: Walter Benjamin e a modernidade de Baudelaire. Kriterion, Belo Horizonte, v. 50, n. 119, 2009. Disponível em <http:// www.scielo.br/scielo.php?pid=S0100-512X2009000100008\&script=sci_arttext $>$.

GEERTZ, Clifford. Nova luz sobre a antropologia. Rio de Janeiro: Jorge Zahar Ed. 2001.

HALL, Stuart. Da diáspora. Identidades e mediações culturais. Belo Horizonte: Editora da UFMG; Brasília: Representação da UNESCO no Brasil, 2003.

LÖWY, Michael. A filosofia da história de Walter Benjamin. Estudos Avançados, São Paulo, v. 16, n. 45, 2002. Disponível em <http://www.scielo.br/pdf/ea/v16n45/ v16n45a13.pdf>.

RICOEUR, Paul. Interpretação e ideologias. Rio de Janeiro: Francisco Alves, 1983.

SANTOS, Boaventura de Sousa. Pela mão de Alice. 0 social e o político na pósmodernidade. São Paulo: Cortez, 2008.

SCOPINHO, Sávio Carlos Desan. Filosofia e Sociedade Pós-Moderna. Crítica filosófica de Gianni Vattimo ao pensamento moderno. Porto Alegre: EDIPUCRS, 2004.

VATTIMO, Gianni (org.). Hermenéutica y racionalidad. Santafé de Bogotá: Editorial Norma, 1994.

VATTIM0, Gianni. O fim da modernidade. Niilismo e hermenêutica na cultura pós-moderna. São Paulo: Martins Fontes, 1996.

. La sociedad transparente. Barcelona: Paidós, 1996. 